\title{
The Application of Multimedia and Network Technologies in College Piano Teaching
}

\author{
Zhihua Zhang \\ College of Teacher Education \\ Qujing Normal University \\ Qujing, Yunnan, China 655011
}

\begin{abstract}
Based on the continuous development of science and technology, the disadvantages of traditional piano teaching mode can be overcome by other types of teaching modes. Furthermore, the application of multimedia and network technologies also contributes to the development of college piano teaching mode. This paper discusses the important role multimedia and network technologies in college piano teaching based on an analysis of the status quo and problems of college piano teaching, and gives some suggestions and schemes for the application of multimedia and network technologies in college piano teaching.
\end{abstract}

Keywords-college piano teaching; multimedia; network; application

\section{Status QuO AND PROBlems OF COLlEGE Piano TEACHING}

At present, there are two major modes in college piano teaching, one is teaching in large class and another one is individual tuition. However, both of two modes, regardless of the advantages either of them has in teaching practice, have noticeable disadvantages [1].

Teaching in large class is a teaching mode typically used in China's universities and accounting for a large proportion, and it is also called as a "popularized" college piano teaching mode with a low cost by which many students are taught by a teacher in a classroom. Teaching in large class is a teacher-centered teaching mode and teachers tend to spend more time in teaching basic piano knowledge, piano playing and appreciation in the teaching process[2]. For this, students are given less time to play piano and besides, most of the students, limited by the number of piano, are unable to get enough practice, making it difficult for the students to incorporate the knowledge acquired from their teachers to piano playing in practice. As a teacher's energy and time is limited, and can not notice the problems every student has, it is difficult for a teacher to give tailored-made lesson for each student's ability. In addition, due to students' difference in ability, the teaching in large class evokes challenge of students' learning process. As can be seen from practice, most of the students taught in large class can not play the piano very well despite of their comprehensive knowledge, having the students with big goal but insufficient ability, and causing low teaching efficiency.
In contrast, to some extent, the said disadvantages of teaching in large class can be overcome by individual tuition mode. Individual tuition is a teaching mode where the students interact one-to-one in a closed environment with a teacher in the teaching/learning process. Individual tuition provides the students with more opportunities to practice playing the piano by themselves based on teacher's explanation[3], which effectively combines knowledge and practice to promote the learning efficiency. Individual tuition gives a teacher with more time to tailor his instruction to meet the student's need based on the student's piano playing skills and then to develop a rational and efficient instruction program, furthermore, the teachers may adjust their instruction programme, in good time based on the student's learning result and performance. Despite of the above advantages, on the one hand, individual tuition is relatively costly to daunt many students for the piano learning and also poses a big challenge for teachers. In individual tuition, a teacher may shoulder more workloads and is exposed to more pressure, impeding regular teaching work in long term. On the other hand, it has some adverse effect on students' psychological quality. The students who get accustomed to the one-to-one mode and absolute playing environment may find it difficult to accommodate themselves to a new environment, consequently, they fail to perform better despite of their good knowledge and piano playing skills, which goes against the students' further growth.

In summary, teaching in large class, although at a low cost, is less effective and efficient, and the students have poor performance in piano playing, in contrast, individual tuition, although highly efficient, is relatively costly, and hinders the development of the students' psychological quality. It is thus vital to introduce new teaching modes for supplementary teaching to college piano teaching, contributing to improving teaching efficiency and promoting the students' all-round development. Moreover, the multimedia and network technologies have gradually matured, it is of good value and practical significance to combine the technology and college piano teaching.

\section{Positive Role OF Multimedia AND NETWORK TEChNOLOGIES IN COLlege PIANo TEACHING}

With the continuous development and progress of science and technology, multimedia and network technologies have been widely and increasingly incorporated to the teaching 
practice with its good presentations, comprehensive information, a wealth of resources and easy application. The introduction of multimedia and network technologies can greatly facilitate the college piano teaching, enrich the learning environment, stimulate the students' interest in learning, develop more teaching resources. In a whole, its advantages can be described below in details.

\section{A. Improve the Efficiency of Piano Teaching}

Multimedia and network technologies can enrich the teaching environment and transform stereotyped instruction and playing practice into auditory and sensory stimulation in an all-round manner and in a variety of formats. Multimedia brings the students to a virtual playing environment to create a good teaching environment so that the students can be better involved in classroom and then to stimulate the students' interest in piano learning[4]. As Mr. Tao Xingzhi discussed on the education, "wisdom of education" is to motivate the students' all senses, and then to stimulate the students' interest in learning and learning efficiency, and to increase the teachers' instruction efficiency. By motivating the students' interest in learning, the focus of classroom is shifted to the students from the teachers, whereby the students are proactive in learning and their initiatives and creativity are inspired. In this way, the teachers get twofold results with half the effort with ease, and the students' active learning is strongly encouraged.

\section{B. Enhance the Students' Ability to Appreciate Beauty}

The piano teachers typically are unable to play a large amount of musical works with the limited ability or to express the emotion some musical pieces contain into their playing accurately and overwhelmingly, while multimedia and network technologies break through such limitation by presenting a variety of musical works and masterful playing to the students in classroom[5]. Being directly exposed to masterful piano performance and combined with the teacher's instruction, the students' ability to appreciate beauty is thus improved. The improvement of ability to appreciate beauty is an improvement of artistic accomplishments, which is essential to the students and contributes to the long-term teaching and learning. There is an old saying that "Speak not of lakes and streams to one who once has seen the sea", the students who have ever been exposed to masterful piano performance will upgrade their requirements and set themselves the higher standards, which is beneficial to teaching and learning. In addition, The improvement of the students' ability to appreciate beauty can drive the students to develop their playing skills, and the development of piano playing skills will improve the students' ability to appreciate beauty in turn, leading to a virtuous cycle to promote the students' piano learning.

\section{Strengthen the Students' Perception of Piano Art}

The application of multimedia and network technologies in college piano teaching enriches and completes the piano teaching process. It is easily acceptable to the students if the abstract and complicated piano knowledge and theory of piano playing are converted into audio, video and other forms of information to present the students a good scene and to allow the students to be immersed in the virtual scene. Furthermore, the conversion of knowledge form makes it easy for the students to get a profound understanding and memory of knowledge and then to develop their own understanding and thoughts of piano playing. In the meanwhile, multimedia and network are a tool to develop the students' thinking space and to stimulate their imagination, so that the students' emotion can be better expressed when they play the piano to enhance the emotional interaction with the piano, whereby the students' perception of piano art will be strengthened.

\section{ThE APPLICATION OF MUltimedia TECHNOLOGY IN COLlege Piano TEACHING}

The application of multimedia technology in college piano teaching takes a variety of forms. The following specifies several forms commonly applied to teaching practice.

\section{A. Use Actively Multimedia to Appreciate Master Player Concert}

The master player concert, although greatly contributing to the students' learning and the teachers' instruction, is not easily available with its high requirements for the students in reality to enjoy the live performance, additionally, some colleges are subject to their own geographical and instructional environment, making it more difficult for them to get exposed to the master player concert, but the use of multimedia to appreciate the master player concert will ease such embarrassing situation. To appreciate master player concert via multimedia helps narrow the gap between the students and the master players to enable the students to enjoy the player's masterful performance and being exposed to good visual and auditory stimuli. A master's classical works which is typically extremely beautiful and leaves one a deep impression, can travel through history even after his death. The multimedia technology can represent the masters' music performance and bring them back to an amazing music world which will impress the students with the maters' extraordinary performance and unparalleled artistic appeal[6].

\section{B. Employ Multimedia Music Software to Engage the Students in the Outward Training}

With the continuous development of people's living standards and the declined personal computer cost, personal computer is becoming increasingly popular and many students have their own computers. In this case, a variety of software is designed specially for music training to contribute to the students' self-study. The professional music software plays a positive role in promoting the students' learning as a supporting tool for classroom instruction, among which, EarMaster, cubase and MusicMaster are commonly used. Specifically, the EarMaster is produced special for rhythm training, benefiting both professionals and non-professionals through the Q\&A mode and the audio-visual method to make learning fun. Another example is the MusicMaster software, a favorite of most of music professionals, and it allows the students to independently write simple musical pieces and pieces for view-sing use only if they learn how to use the software. The creation process can fully motivate the students' 
imagination and creativity, in this sense, every beat is a soldier featured with the students' personality. The said supporting instruction mode gives the advantages of network resource to its full play and effectively and efficiently utilizes the computer-centered multimedia technology, and emphasizes the students' sustainable development.

\section{Make the Most of the Role of Multimedia Digital Piano in Teaching}

At present, digital piano classrooms have become one of the popular teaching modes in universities and colleges to facilitate the piano teaching based on large classes, which can be said as the fruit of scientific and technological progress. On the one hand, it promotes the piano playing skills training in the teaching process, reduces the teachers' workloads after colleges' enrollment expansion, and contributes to the optimization and improvement of music instruction quality. On the other hand, one-to-one instruction interaction and new instruction concept are incorporated to multimedia digital piano classroom where the students and the teachers may get more interaction and communication to make piano learning more fun. The multimedia music education system used for digital piano classroom helps create a desirable "educational entertainment" environment in a comprehensive manner with its initiative, communicative, motivational, graphic, incentive, tailor-made and depersonalized features in music learning.

\section{APPliCATION OF Network TEChNOLOGY IN COLLEGE PIANO TEACHING}

\section{A. Use Network Search}

Network search is commonly used the Internet technology. Although there is a massive amount of resources on the Internet, search engine has powerful search function and returns index-based files, video, audio and other formats of information search results to the users who enter the key words. A piano teacher who has a unique perception of and sufficient experience on piano art and piano instruction will recognize the only way to have a profound understanding of the subject and meaning of the musical works itself is to incorporate creation background and subject matter of the works. To get a deeper understanding of most of works itself, historical background and cultural background are strategically needed rather than solely relying on works analysis. In this regard, the Internet is greatly helpful with the contained massive information. The diverse information available on the Internet breaks the interdisciplinary barriers and returns to the students all-round information based on the students' works-indexed search to enable the students to appreciate and understand the works from other perspectives. Teachers are suggested to assign a set of tasks to the students to complete out of the class after teaching a new piece of music, including searching the information on the composer of the musical pieces the student plays, the composer's style, historical background, etc., through which, the students' understanding and recognition of the musical piece will be further strengthened[7].

\section{B. Piano Learning and Communication via Online Forums and Wechat}

In reality, the students generally communicate with their teachers and clubs associated with the students' major for help when it comes to piano learning, which has a certain limitation and suppresses the students from thinking and learning from a new perspective. While, online communication is more convenient and facilitates the students in getting acquainted with different types of friends, being a great help to the students' self study. For online learning, online forum is a relatively traditional and popular learning mode. The browser returns a number of search results related to piano forums and websites after we enter the "piano forum" search queries. The existing authoritative piano forums mainly include "Starry Night Piano Forum" and "Chongchong Piano Forum", and "Popular Piano Website" is a website concerning popular piano. Forum provides the students with a relaxed and flexible platform for piano learning where the students not only appreciate others' musical pieces, but also upload the works they played for others' comments. Besides, as some of the questions asked on forums have similarities, the students may reflect on themselves based on others' answers to continuously improve themselves.

Wechat official account is a new network format and is very popular nowadays. A number of official accounts search results are provided in response to the piano-related search queries. The information of Wechat official account is updated weekly or daily on a regular basis, and besides, the students can find many online piano knowledge from Wechat official accounts to encourage the students' development of own learning methods and process. Beyond that, the students may build a Wechat group to get discussions and experience exchange, enriching communicative means and reducing the limitations on time and places. The relaxed and flexible environment encourages the students' initiative and promotes the students' learning.

\section{Make the Most of Network Resources}

The Internet with its abundant resources provides a good platform for piano learning where people can find a considerable amount of sheet music, concert video and audio in all formats, and these resources greatly enrich the teachers' instruction and the students' self-study. Network resources is becoming increasingly abundant, providing us with a growing space for use. For example, we may visit www.sooopu.comor other websites to find the sheet music we need, Yihong Kuailv Forum, or VERYCD website to download the audio or video of musical pieces we want, www. dangdang. com or Amazon. $\mathrm{cn}$ and other e-commerce websites to buy pianos, CD, DVD and all things related to piano you desire. All you need to do is a computer that offer access to Internet and you can operate a mouse to get all the resources[8].

\section{With the Rapid Popularity of Digital TV and Internet TV in Families, An Increasing Range of Events and News Is Broadcast on the Internet}

Compared with ordinary television signal, digital TV and network TV have more advantages because of allowing viewing at any time. For ordinary TV, users, if missing 
specific broadcast time, will have no opportunity to watch the content again. However, digital TV and Internet TV allow the users to view the videos on demand at any time they desire rather than having to view it at the real broadcast time. If the trends continues, various piano competitions and concerts are likely available from the Internet in the near future, and the users can appreciate the concerts at any time regardless of the real broadcast time.

\section{CONCLUSION}

Information technology support, Internet platform establishment and the integrated multimedia application provide a whole new world for the modern piano teaching and piano playing, and multimedia and network technologies create a great space for use no matter for piano playing or piano teaching. The reasonable application of multimedia and network technologies has positive significance for college piano teaching. This paper discusses some schemes for the application of multimedia and network technologies in college piano teaching in hopes to provide a certain value for college piano teaching.

\section{REFERENCES}

[1] Li Wei, Dan Xia. A Brief Analysis of the Permeation of Multimedia and Network Technologies to Piano Teaching and Piano Playing [J]. Science and Technology Information (science and research), 2008,05: $38+100$.

[2] Xiong Yiping. The Application of Multimedia and Network technologies in College Piano Teaching [J]. APPRECIATION, 2016,04:284.

[3] Zhang Yang. An Analysis on the Permeation of Multimedia and Network Technology to Secondary Vocational School's Piano Teaching [J]. Time Education, 2015,08:93.

[4] Li Chunxiao. The Application Research of Multimedia Technology in College Piano Teaching [J]. Northern Music, 2015,05:110.

[5] Lei Ying. The Application of Multimedia Technology in College Piano Teaching [J]. Academic Journal of Hezhou University, 2015,02:132-134.

[6] Feng Haiyan. Application Practice and Prospects of Multimedia Technology in College Piano Teaching [J]. Time and Space in Music, 2014,20:150.

[7] Li Wei, Su Yuanyuan. A Brief Discussion of the Permeation of Multimedia and Network Technologies to Secondary Vocational School's Piano Teaching and Piano Playing [J].Chinese Information and Technology Education, 2014,12:28+30.

[8] Rao Tingting. A Brief Analysis of the Permeation of Multimedia and Network Technologies to Piano Teaching and Piano Playing [J]. Reading Digest,2014,12:77. 